\title{
Wing wear is a poor estimate of age in Cerceris fumipennis (Hymenoptera, Crabronidae)
}

\author{
Christine A. Nalepa' \\ I Beneficial Insects Laboratory, Plant Industry Division, North Carolina Department of Agriculture \& Consu- \\ mer Services, 1060 Mail Service Center, Raleigh, NC 27699-1060 \\ Corresponding author: Christine A. Nalepa (christine.nalepa@ncagr.gov)
}

Academic editor: J. Neff | Received 14 September 2011 | Accepted 28 September 2011 | Published 10 January 2012

Citation: Nalepa CA (2012) Wing wear is a poor estimate of age in Cerceris fumipennis (Hymenoptera, Crabronidae). Journal of Hymenoptera Research 24: 43-46. doi: 10.3897/JHR.24.2091

The native, ground nesting, beetle hunting philanthine wasp Cerceris fumipennis Say is in development as a biosurveillance tool to detect Emerald Ash Borer (Agrilus planipennis) and other pest Buprestidae threatening the forests of North America (Marshall et al. 2005; Careless and Marshall 2010; Nalepa and Swink 2011). As part of that effort the North Carolina (NC) Department of Agriculture \& Consumer Services has been working to determine the phenology and life history of $C$. fumipennis in the state, primarily to determine its activity overlap with prey species of interest. An examination of specimens in the NC State University Insect Museum indicated that $C$. fumipennis had been collected in Wake County, NC, as early as 24 May and as late as 22 September between 1921 and 1982, and Kurczewski and Miller (1984) noted that C. fumipennis probably has a partial second brood in the south. Observations of wing wear of $C$. fumipennis females in Wake County during 2009 suggested that there may be either an extended emergence of a single generation, or that more than one generation per year occurs in the state. During the third week of July, females with completely intact wings as well as females with severely damaged wing margins were both present in the same nesting aggregation. In 2010 a study was conducted at that aggregation, a baseball diamond in the Raleigh City Parks system, to determine if wing wear in C. fumipennis may be positively correlated with female age.

Shortly after nests began appearing at the site (30 May), females were captured and given a unique mark on the thorax using DecoColor opaque paint markers (Fig. 1a). A picture of each marked female's right wing was taken with a Sony Cybershot

Copyright Christine A. Nalepa. This is an open access article distributed under the terms of the Creative Commons Attribution License 3.0 (CC-BY), which permits unrestricted use, distribution, and reproduction in any medium, provided the original author and source are credited. 

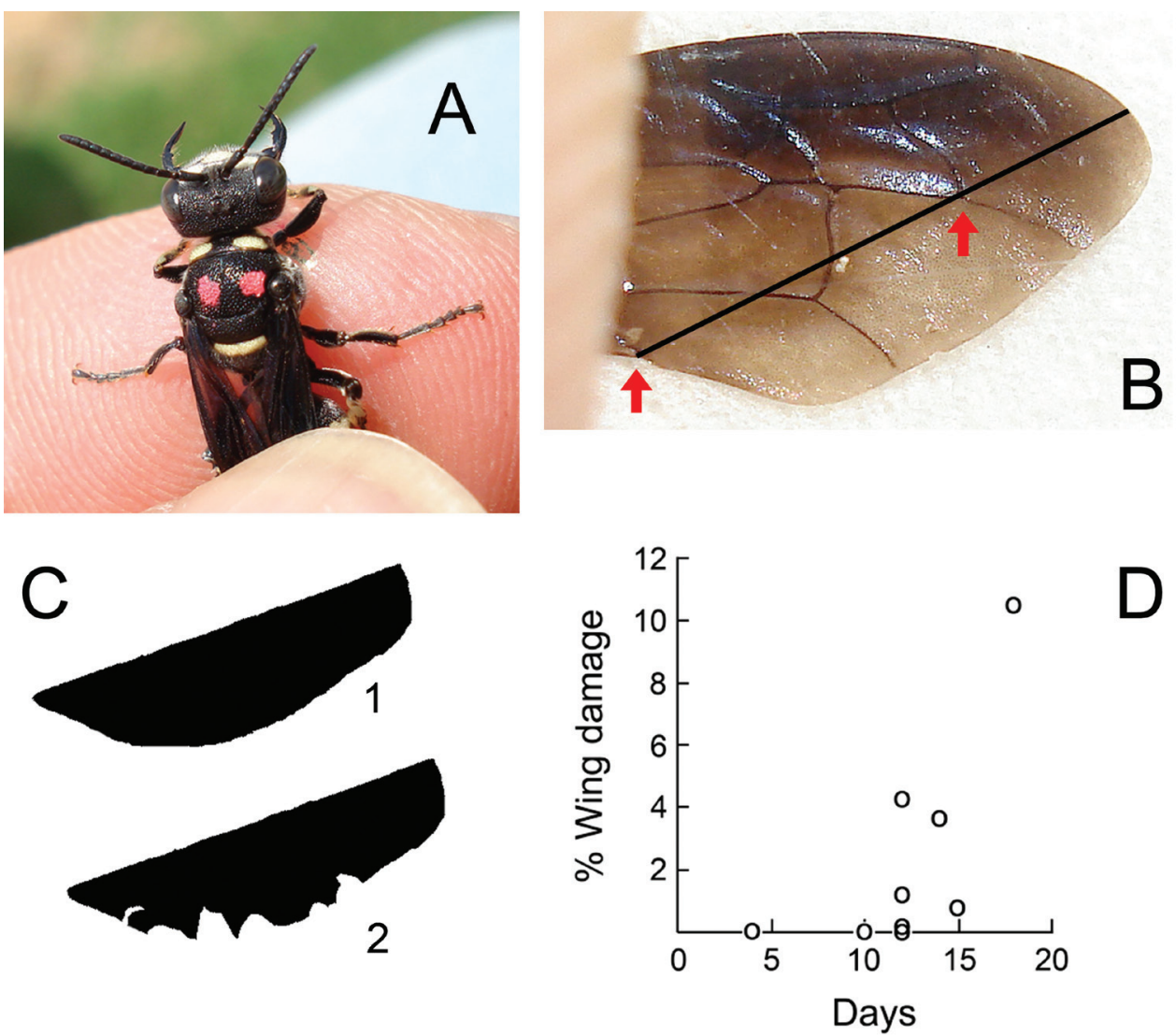

Figure I. Technique used in attempting to determine number of Cerceris fumipennis generations per year based on wing wear. A Marked female; B Field photograph of right wing, showing reference points for analysis; $\mathbf{C}_{1}$ Undamaged wing of Female \#2 (30 May); $\mathbf{C}_{2}$ Damaged wing 18 days later. D Plot of percent wing damage over time in 9 females, based on pixel counts of before (baseline) vs. after wings.

camera, and the wasp was then released. Subsequently, 11 visits were made to the site over the active season, and during each, an attempt was made to capture and examine all active wasps. If a female hadn't been previously captured, she was marked and her wing condition recorded. In all recaptured females, wing condition was documented if it had been more than 5 days since she was last seen. Four site visits were made during the first week of wasp activity; subsequently, visits were made at least every 2 weeks until the end of the active season at that site (26 July).

A total of 32 females were marked between 30 May and 12 July, and in $23(72 \%)$ the wing was completely undamaged when the female was first captured. Nearly half (47\%) of marked females were never recovered. Eight females were recaptured between 10 and 18 days after initial marking. One was found dead on the field 4 days after marking, an apparent casualty of a human foot. Wing damage in these nine wasps was analyzed using the before (baseline) and after photographs, based on the technique of Lehnert (2010). A standard portion of the wing was delineated in Adobe Photoshop ${ }^{\oplus}$ 
(Version 9.0.2) by drawing a line through two reference points: where vein $C u_{1 \mathrm{~b}}$ meets the wing margin, and at the junction of $M$ and $3 r-m$ (Fig. 1b). That portion of the image was excised, the color removed, and the contrast adjusted so that the wing appeared black on a white background (Fig. 1c). ImageJ software (National Institute of Health, public domain) was then used to obtain pixel counts in the before and after wing tips to estimate percent wing damage. Percent damage was plotted against the number of days elapsed between the before and after photographs to determine if wing damage could be correlated with a given female's age.

The relationship between days elapsed and percent wing damage was inconsistent (Fig. 1d). A few females contributed to a trend of increased damage with time, but in others, the wings remain intact or nearly so over the same period. The wings of two females were completely unchanged over a 10-12 day interval. The results indicate that wing damage is of little use in assessing $C$. fumipennis age and consequently the number of generations of the wasp in central NC. Wing damage probably results primarily from digging and maintaining a nest and intraspecific aggression, and is therefore likely to be associated with behavioral variation. Females of $C$. fumipennis obtain nests by re-using their natal nest, digging a new one, or usurping one from another female; contention of nest ownership may involve brief fights (Mueller et al. 1992). A female that digs a nest in hard substrate, then defends it from a number of conspecifics would be prone to more wing wear than one that claims ownership of a relatively uncontested existing nest. Both substrate characteristics and nesting strategy, then, would contribute to variation in wing wear. Although not examined in the present study, mandibular wear may exhibit similar behavior dependent variation. In conclusion, wing wear is not an appropriate measure of female age in C. fumipennis, but the Lehnert (2010) technique may be of use in other hymenopteran taxa.

\section{Acknowledgements}

I thank Lynn Warren and the Raleigh Department of Parks and Recreation for permission to work on the ball diamond. The study was funded by Forest Health Protection, USDA Forest Service.

\section{References}

Careless P, Marshall SA (2010) Working with the smoky-winged beetle bandit. Bulletin de la Société d'entomologie du Canada 42: 25-29. [http://www.cerceris.info/pdf/esc_bulletin_\%20careless\&marshall.pdf]

Kurczewski FE, Miller RC (1984) Observations on the nesting of three species of Cerceris (Hymenoptera: Sphecidae). Florida Entomologist 67: 146-154. doi: 10.2307/3494114

Lehnert M (2010) New protocol for measuring Lepidoptera wing damage. Journal of the Lepidopterist's Society 1: 29-32. 
Marshall SA, Paiero SM, Buck M (2005) Buprestid sampling at nests of Cerceris fumipennis (Hymenoptera: Crabronidae) in southern Ontario: the first Canadian records of three buprestids (Coleoptera: Buprestidae). Canadian Entomologist 137: 416-419. doi: 10.4039/ n05-016

Mueller UG, Warneke AF, Grafe TU, Ode PR (1992) Female size and nest defense in the digger wasp Cerceris fumipennis (Hymenoptera: Sphecidae: Philanthinae). Journal of the Kansas Entomological Society 65: 44-52.

Nalepa C, Swink W (2011) Hemlock borers collected by the native wasp Cerceris fumipennis in the North Carolina mountains. North Carolina Pest News 26 (11): 7. http://ipm.ncsu. edu/current_ipm/pest_news.html 